tumours is the product of one of the cellular oncogenes. ${ }^{910} \mathrm{It}$ inay, after all, be possible to reduce a complex clinical problem to a system simple enough to be analysed by a mere laboratory scientist.

\section{MIRANDA ROBERTSON}

Staff Editor,

Nature,

London WC2R 3LF

1 Tabin CJ, Bradley SM, Bargmann CI, et al. Mechanism of activation of a human oncogene. Nature $1982 ; 300: 143-9$.

${ }^{2}$ Reddy EP, Reynolds RK, Santos E, Barbacid M. A point mutation is responsible for the acquisition of transforming properties by the T24 human bladder carcinoma oncogene. Nature 1982;300:149-52.

${ }^{3}$ Robertson $\mathrm{M}$. Oncogenes and the origins of human cancer. $\mathrm{Br} \mathrm{Med} \mathcal{F}$ $1983 ; 286: 81-2$

4 Logan J, Cairns J. The secrets of cancer. Nature 1982;300:104-5.

${ }^{5}$ Land H, Parada LF, Weinberg RA. Tumorigenic conversion of primary embryo fibroblasts requires at least two cooperating oncogenes. Nature $1983 ; 304: 596-602$.

${ }^{6}$ Ruley HE. Adenovirus early region $1 \mathrm{~A}$ enables viral and cellular transforming genes to transform primary genes in culture. Nature $1983 ; 304$ : 602-6.

7 Godbout R, Dryja TP, Squire J, Gallie BL, Phillips RA. Somatic inactivation of genes on chromosome 13 is a common event in retinoblastoma Nature 1983;304:451-3.

${ }^{8}$ Newbold RF, Overell RW. Fibroblast immortality is a prerequisite for transformation by EJ c-Ha-ras oncogene. Nature 1983;304:648-51.

9 Waterfield MD, Scrace GT, Whittle N et al. Platelet-derived growth factor is structurally related to the putative transforming protein p $28^{\text {sis }}$ of simian sarcoma virus. Nature $1983 ; 304$ :35-9.

10 Doolittle RF, Hunkapillar MW, Hood LE et al. Simian sarcoma virus onc gene, $\mathrm{v}$-sis, is derived from the gene (or genes) encoding a plateletderived growth factor. Science $1983 ; 221: 275-7$.

\section{Inner cities: time for a cure?}

Two years ago a $B M \mathcal{F}$ leading article" stated that "inner cities have some of the worst social and medical problems combined with some of the poorest primary care." Shortly afterwards the Acheson report on Inner London was published, giving hope that the government might be prepared to finance reform and restructuring of primary care in the most deprived parts of our cities. ${ }^{2}$ These hopes have now been dashed by the cutbacks in National Health Service expenditure. Yet the problems remain: in the wake of the Acheson report other studies have confirmed the social and environmental problems facing doctors who choose to work in these areas. $^{3-6}$

The use of the generic term "inner cities" has not helped -indeed, it has almost a pejorative ring to it. In reality the problems vary from city to city, from borough to borough, and even from street to street. Attempts to ascribe one cause or prescribe one solution to the multiple and complex problems produced by varying environments and circumstances are doomed to failure. Sensational treatment by journalists of the various medical and social aspects of inner city problems has made matters worse-while professional and political idealists have pursued their own particular philosophies with little regard to logic or the consequences.

In London, for example, the problems are said to include the rumbers of elderly singlehanded doctors, practices with a small list size, unsuitable premises, and lack of available staff, together with a considerable lack of interest in supporting primary care by some planning authorities and teaching hospitals. Wood has shown that these are not the main problems in Manchester, where the prime difficulty is attracting young doctors to the area. ${ }^{6}$ I have found that, though several common threads run through the pattern of problems in different cities, each needs to be considered on its own merits and with regard to local resources. ${ }^{4}$

Medical, social, and environmental factors may all contribute to the difficulties facing providers of primary care in our cities. The medical factors include elderly doctors, list size, the Medical Practices Committee's recruitment policies, low practice income, non-availability of doctors out of hours, overseas doctors, attitudes of teaching hospitals, lack of a primary health care team, high psychiatric-social caseload, and a poor public image. These are likely to be aggravated by the social factors-a high proportion of the population being mobile (but with many elderly patients living alone), single parent families, high rates of crime and unemployment, and concentrations of ethnic minorities; and the physical setting is likely to be decaying with inadequate or inappropriate urban development programmes and a lack of accommodation suitable for primary care.

These problems have been allowed to develop and then to persist as a consequence of medical inertia or indifference, political dogma affecting rational urban development, and a chronic lack of financial resources. The leading article quoted above went on to state that "the traditional buttresses of primary care [are] the acute hospital and social services." The attitude this statement reflects may explain why some of the problems have arisen. In most parts of Britain general practitioners would not consider themselves to be buttressed by the hospital or social services-indeed, quite the opposite. These and other attitudes will have to change if inner city problems are to be solved.

Of course, the personal examples of success by some doctors and administrators shine brightly in the otherwise drab uniformity of inaction and discouragement, but these are few. Medicopolitically the profession has little to be proud of. For example, until recently the policies of the Medical Practices Committee successfully blocked the appointment of young vocationally trained doctors to vacancies in inner city practices. Successive governments and local authorities have carefully ignored facts or difficulties which did not fit in with their own particular policies, and resources have not been made available - or have been, but only very slowly.

By contrast, those departments of general practice which have become actively concerned with the provision of inner city care have improved the standards of the practices with which they work. The establishment of two more chairs of general practice in London is very welcome (provided they are given the necessary resources). Yet the average general practitioner perceives academic general practice as being remote from reality. This impression could be effectively disproved if the departments united to coordinate their efforts to raise standards of care uniformly throughout Britain. The profession and the public have to acknowledge that two standards of primary care are now being offered to our population. In recent years the General Medical Services Committee and the Royal College of General Practitioners have worked closely together on several important issues, and they could cement their new relationship by taking the initiative for action. With the university departments of general practice they would make a powerful triumvirate that should be able to propose general policies for solution of the various problems-though these policies would need modification according to local circumstances-and persuade general practitioners to adopt them.

Clearly in its current mood of cut and freeze the DHSS has swept away all thought of acting on the Acheson report. ${ }^{2}$ 
The profession will have to work out its own solutions. Is it equal to the challenge?

K J BOLDEN

Senior Lecturer in General Practice,

Postgraduate Medical School,

University of Exeter,

Exeter EX2 5DW

1 Anonymous. Primary care in inner London: inadequate and exposed. Br Med F $1981 ; 282: 1739-40$.

${ }^{2}$ London Health Planning Consortium Study Group on Primary Health Care in Inner London. Report. London: DHSS, 1981. (Acheson report.)

3 Jarman B. Survey of primary care in London. London: Royal College of General Practitioners, 1981. (Occasional Paper, No 16.)

- Bolden KJ. Inner cities. London: Royal College of General Practitioners, 1981. (Occasional Paper, No 19.)

5 Department of Health and Social Security. Inequalities in health. London: DHSS, 1980. (Black report.)

${ }^{6}$ Wood J. Are the problems of primary care in inner cities fact or fiction ? Br Med f 1983;286:1109-12.

\section{The employment of diabetics}

The success of individual diabetics in sport or athletics is often applauded in the media, but there is still considerable confusion in the minds of employers-and even some doctors-about the suitability of diabetics for various types of employment and about their reliability as employees.

Much of this confusion is due to a lack of understanding about the difference between the treatment of insulin dependent diabetics and non-insulin dependent diabetics and to misconceptions about the nature and incidence of diabetic complications and the disabilities they are likely to cause. Doctors must, therefore, understand the position themselves and take every opportunity to clarify it for others.

Diabetics controlled by diet alone and free of romplications should be able to follow any occupation, while those who are controlled by diet and oral treatment and are free of complications and not subject to hypoglycaemia should be able to follow alnost any occupation. Even insulin dependent diabetics are suitable for most occupations, but they must not be employed in a job where hypoglycaemic reactions could endanger themselves or other people. Thus they should not work on scaffolding, or near moving machinery, nor should they drive public service or heavy goods vehicles. They are not eligible for service with the armed forces, nor will they be granted a commercial airline pilot's licence or be able to drive a passenger train.

Unfortunately, diabetic retinopathy, nephropathy, and neuropathy may occur in both types of diabetes. Failing vision due to retinopathy and recurrent ulceration of the feet are two of the most disabling complications, but these affect only a few diabetic patients in a form severe enough to compromise their prospects for employment.

Little research has been done recently to determine the work record of diabetics, but a recent paper on the employment of diabetics ${ }^{1}$ quoted earlier surveys ${ }^{2}{ }^{3}$ which all confirmed that on the whole diabetics are good employees from the standpoint of attendance and length of service. As with non-diabetic employees, about half the absences from work among diabetics are due to respiratory or gastrointestinal disorders. Diabetics do not appear to be any more liable to accidents at work than non-diabetics, but they do have slightly more absenteeism due to sickness, especially those with more severe insulin dependent disease.
Shift work has often been considered unsuitable for diabetics because of the problem of adjusting the diet and the dose of insulin to a changing pattern of work, mealtimes, and rest. In fact, shift work presents no real problem for the noninsulin dependent diabetic, and with appropriate advice from his physician and dietitian the reasonably intelligent insulin dependent diabetic can make the necessary adjustments to his dietary and insulin regimen.

Driving presents a particular problem for insulin dependent diabetics. As stated above, such people should not hold either a licence to drive a public service vehicle or a licence to drive a heavy goods vehicle. Many occupations, however, require driving motorcars or light vans for which no special licence is required. It is for the employer to satisfy himself that any diabetic driver whom he employs is responsible and competent in managing his diabetic control. He should also seek confirmation that the driver has notified the Driver and Vehicle Licensing Centre about his diabetes and that his own or the company motor insurers have also been notified. The employed diabetic driver must be frank in all matters relating to his diabetes. Concealing the fact of his diabetes or of his liability to hypoglycaemia may have serious consequences in the event of an accident.

Mastbaum et $a l^{4}$ considered that the satisfactory placement of a diabetic in industry depends on the frequency and severity of hypoglycaemia, the adequacy of medical supervision, and the prevalence or absence of complications. It also depends on an enlightened attitude on the part of the employer and a responsible attitude on the part of the diabetic employee. Some employers may be reluctant to employ any diabetics, in the mistaken belief that they are likely to be unsatisfactory employees; others have been reluctant to employ diabetics because of the fear of future problems, while difficulty in negotiating superannuation arrangements on account of the associated life insurance may present an immediate problem, but one that can usually be overcome. Some diabetics believe that they have been discriminated against when applying for posts, either failing to achieve an interview or being passed over at interview in favour of a non-diabetic applicant. Such views are hard to substantiate but faced with two otherwise equally suitable applicants an employer might well select the non-diabetic, and in times of high unemployment the diabetic may find more than average difficulty in obtaining work.

Most newly diagnosed diabetics-certainly those who are insulin dependent-experience feelings of apprehension, inadequacy, and insecurity, and one of the physician's tasks is giving his patient confidence that he will be able to cope. Once this confidence has been gained and the treatment prescribed has restored a sense of wellbeing most diabetics will show considerable determination to live reasonably normal lives and will not allow their condition to interfere with their work. Indeed Soskin, ${ }^{5}$ citing his personal experience with the diabetic employee, observed that "the feeling engendered by the non-prejudicial acceptance of his handicap is apt to make him an unusually hard working and loyal employee."

While increasing emphasis is being given to ways of sharing the care of diabetics between hospital specialists and general practitioners most diabetics still appreciate the security provided by regular attendance at a diabetic clinic where dietetic advice and other educational facilities should be available. Employers should be willing to allow diabetic employees time off to attend their clinics. General practitioners should receive brief reports about their patients after each clinic attendance, and if there are problems specifically related to a diabetic's 